\title{
Respon Masyarakat Lokal terhadap Pengembangan Kebun Raya Gianyar sebagai Destinasi Pariwisata di Desa Kerta
}

I Putu Ardita Yadnya a, 1, I Made Adikampana a, 2

1 ardita.yadnya@gmail.com,2 adikampana@unud.ac.id

a Program Studi Sarjana Destinasi Pariwisata, Fakultas Pariwisata,Universitas Udayana, Jl. Dr. R. Goris, Denpasar, Bali 80232 Indonesia

\section{Abstract}

Gianyar Botanical Garden is one of the environmental conservation which will also be developed into a tourist destination in the village of Kerta. A tourist destination is a place that is owned, facilities, access and community related to him. The development of the Gianyar Botanical Garden as a tourist destination must have the authority, facilities, access and most importantly a positive response from the local community so that tourism in the Gianyar Botanical Garden can run well. Therefore, a research is needed to find out the community's response to the development of the Gianyar Botanical Garden as a tourism destination in Kerta Village.

The method used techniques to analyze tourism product data in the Gianyar Botanical Garden and the local community response. Then used a method with descriptive statistical to analyze local community response data obtained through questionnaires. Data collection techniques using observation, interviews, questionnaires and literature studies. The informant determination technique uses purposive sampling. The technique of determining respondents uses the Slovin formula. To find out the local community response using the concept of local community response (Swastha and Handoko, 1997).

The stages of developing the Gianyar Botanical Garden at the Involvement stage where tourism product development began to be carried out on attractions, facilities, access, marketing and planning. The response of the local community to the development of the Gianyar Botanical Garden as a tourism destination as a whole is very positive or Euphoria where local communities have welcomed the presence of tourism by giving them the trust and approval of community wishes fulfilled, information to local communities regarding the development of the Gianyar Botanical Garden and local communities participating voluntarily.

Keywords $\quad$ : Local Community Response, Tourism Development.

\section{PENDAHULUAN}

Perkembangan industri pariwisata di Bali memberikan dampak yang besar kepada masyarakat lokal, baik itu dari aspek perekonomian, sosial budaya maupun dari aspek lingkungan. Dampak yang diberikan dari kepariwisataan dibali begitu besar dari aspek ekonomi. Namun sangat disayangkan, hal tersebut berbalik dengan dampak sosial budaya dan lingkungan yang didapat. Perkembangan pariwisata membuat banyaknya alih fungsi lahan yang digunakan untuk menunjang kegiatan pariwisata, pencemaran lingkungan dan menurunnya nilai - nilai sosial dalam masyarakat (Evita dkk, 2012)

Pariwisata bali kedepannya diharapkan lebih mengutamakan prinsip - prinsip penyelamatan lingkungan dengan melindungi nilai - nilai sosial yang ada dalam masyarakat serta memberikan keuntungan ekonomi kepada masyarakat. Salah satu bentuk wisata yang mengedepankan ketiga prinsip tersebut adalah ekowisata (Arida, 2006). Ekowisata ialah salah satu bentuk dari pariwisata yang dapat memberikan keuntungan terhadap lingkungan, sosial budaya dan ekonomi (Khan, 2003). Ekowisata dapat dikemas dengan beberapa bentuk yang salah satunya berupa taman. Terdapat beberapa taman yang terletak di Kabupaten Gianyar yang salah satunya yaitu Kebun Raya Gianyar.

Kebun Raya Gianyar merupakan suatu tempat pelestarian lingkungan yang terletak di Banjar Dinas Pilan, Desa Kerta, Kecamatan Payangan, Kabupaten Gianyar. Sebagai destinasi pariwisata yang sedang berkembang di Kabupaten Gianyar, Kebun Raya Gianyar dituntut agar dapat memenuhi aspek - aspek destinasi pariwisata. Menurut Undang - Undang Republik Indonesia Nomor 10 Tahun 2009 tentang kepariwisataan menjelaskan bahwa destinasi pariwisata harus memiliki daya tarik wisata, fasilitas umum, fasilitas pariwisata, aksesibilitas dan masyarakat yang saling terkait didalamnya. Sehingga nantinya Kebun Raya Gianyar dapat menjadi destinasi pariwisata yang berkelanjutan. Pada saat memberikan respon, masyarakat lokal memiliki tingkat kepekaan yang berubah terhadap pengembangan pariwisata (Doxey, 1975). Penelitian ini memakai teori Irritation index yang digunakan untuk mengetahui tingkat kepekaan masyarakat pada pengembangan Kebun Raya Gianyar. 
Penelitian sebelumnya dari Gunarsa (2016) yang berjudul "Respon Masyarakat Lokal terhadap Pengembangan Pariwisata di Kelurahan Seminyak, Kecamatan Kuta, Kabupaten Badung, Provinsi Bali". Dalam penelitian ini dijelaskan bahwa tingkat perkembangan kepariwisataan di Seminyak sangat berpengaruh dengan respon masyarakat lokal dimana pada penelitian ini respon masyarakat lokal akan dikaitkan dengan indikator dampak pariwisata yaitu lingkungan, sosial budaya, ekonomi dan tingkat kunjungan wisatawan. Penelitian ini dapat dijadikan sebuah pedoman dalam menganalisa respon masyarakat lokal sesuai dengan fokus pada penelitian.

Telaah penelitian selanjutnya yaitu oleh Abdilah, dkk (2015) dengan judul "Perkembangan Destinasi Pariwisata dan Kualitas Hidup Masyarakat Lokal.". Dalam penelitian ini menjelaskan bahwa perkembangan destinasi pariwisata dan persepsi masyarakat lokal terhadap kualitas hidup mereka dari adanya pengembangan destinasi pariwisata. Hasil penelitian menunjukkan bahwa perkembangan destinasi pariwisata merupakan peningkatan jumlah wisatawan yang datang serta menambahkan atribut destinasi dan diharapkan dapat mengangkat kualitas hidup masyarakat lokal.

Penelitian oleh Gunawan (2016) yang terbit dalam jurnal yang berjudul "Pengembangan Agrowisata untuk Kemandirian Ekonomi dan Pelestarian Budaya di Desa Kerta, Payangan, Gianyar". Dalam jurnal ini menjelaskan bahwa Desa Kerta mempunyai potensi alam yang sangat besar dalam pengembangan agrowisata yang didukung dengan potensi pertanian dan budaya. Potensi ini diharapkan dapat dikembangkan guna untuk membangun kemandirian masyarakat dalam meningkatkan perekonomian serta kesadaran dalam menjaga lingkungan.

Penelitian oleh Adikampana, dkk (2015) dalam jurnal yang berjudul "Partisipasi Masyarakat Lokal dalam Pengembangan Kawasan Pariwisata Candidasa". Jurnal ini menjelaskan partisipasi masyarakat lokal di kawasan pariwisata candidasa yang diidentifikasi praktik pertukaran modal antara masyarakat lokal dengan industri pariwisata dan kemudian ditentukan jenis partisipasi dalam pengembangan kawasan pariwisata candidasa.

Pengembangan Kebun Raya Gianyar sebagai destinasi pariwisata selain harus memiliki atraksi, fasilitas dan akses, pengembangan Kebun Raya Gianyar juga harus ditopang oleh masyarakat lokal agar kepariwisataan dapat berjalan berkelanjutan. Penelitian ini dilakukan untuk mengetahui respon yang diberikan oleh masyarakat lokal terhadap pengembangan Kebun Raya Gianyar menjadi suatu destinasi pariwisata baru. Sehingga kedepannya dapat dijadikan sebagai acuan terhadap pengembangan Kebun Raya Gianyar.

\section{METODE PENELITIAN}

Penelitian yang dilakukan bertujuan untuk mengetahui respon masyarakat lokal yang nantinya dapat dijadikan sebagai acuan dalam pengembangan Kebun Raya Gianyar kedepannya. Penelitian dilaksanakan di sekitar Kebun Raya Gianyar atau lebih tepatnya di Banjar Adat Pilan, Desa Kerta, Kecamatan Payangan, Kabupaten Gianyar. Lingkupan permasalahan yang dibahas adalah mengenai respon masyarakat lokal yang akan dilihat dari tiga aspek yaitu sikap, persepsi dan partisipasi. Metode penelitian menggunakan deskriptif kualitatif dan statistik deskriptif. Sedangkan jenis data yang dipakai adalah data kualitatif dan data kuantitatif.

Sumber data pada penelitian ini yaitu data primer yaitu data yang didapat di lokasi penelitian dan data sekunder. Teknik pengumpulan data menggunakan observasi, studi kepustakaan dan wawancara dan kuesioner. Teknis analisis data yang digunakan dalam penelitian ini adalah analisis statistik deskriptif, yaitu menggunakan Skala Likert dengan cara mencari frekuensi serta rata - rata respon masyarakat lokal yang meliputi sikap, persepsi dan partisipasi masyarakat lokal yang kemudian data tersebut akan disusun dalam bentuk grafik yang disertai dengan penjelasannya dengan kualitatif.

\section{III.HASIL DAN PEMBAHASAN}

\subsection{Gambaran Umum Kebun Raya Gianyar}

Keberadaan Kebun Raya Gianyar berawal dari Rencana Pembangunan Jangka Menengah Desa yang dibuat oleh I Made Gunawan, 
S.P.,M.Par. selaku Kepala Desa Kerta yang kemudian direspon oleh Pemerintah Daerah Kabupaten Gianyar. Kemudian pada Pemerintah Daerah Kabupaten Gianyar melakukan peninjauan ke lokasi yang dilanjutkan dengan permohonan pengkajian terhadap kelayakan hutan untuk dikembangan sebagai kebun raya kepada Kebun Raya Eka Karya Bali bersama Lembaga Ilmu Pengetahuan Indonesia.

Kajian yang telah dilakukan mendapatkan hasil bahwa hutan yang berada di Banjar Adat Pilan layak untuk dijadikan sebuah kebun raya. Setelah adanya hasil tersebut kerjasama antara Pemerintah Kabupaten Gianyar dengan masyarakat lokal dilakukan dengan penandatanganan nota kesepahaman atau memorandum of understanding. Pada tangal 17 Juli 2017 telah dilaksanakan soft opening secara resmi oleh Lembaga Ilmu Pengetahuan Indonesia (LIPI) serta peresmian prasasti oleh Bupati Gianyar. Soft opening ini bermaksud untuk memberikan ruang kepada masyarakat banyak untuk lebih mengenal atau mengetahui keberadaan Kebun Raya Gianyar itu sendiri.

Keberadaan Kebun Raya Gianyar yang pada saat ini masih dalam proses pembangunan dimana beberapa atraksi telah dibangun untuk dapat dikunjungi yaitu taman tematik, taman anggrek, tempat pembibitan dan hutan adat. Selain atraksi, Kebun Raya Gianyar juga telah membangun beberapa fasilitas seperti pintu masuk dengan arsitektur tradisional bali, lobi dan toilet. Peningkatan akses menuju Kebun Raya Gianyar telah dilakukan melaui pelebaran jalan yang melibatkan peran pemerintah serta masyarakat lokal sehingga akses menuju Kebun Raya Gianyar dapat diakses dengan lancar.

\subsection{Respon Masyarakat Lokal terhadap Pengembangan Kebun Raya Gianyar}

\subsubsection{Sikap Masyarakat Lokal}

Pengembangan Kebun Raya Gianyar mendapatkan sikap yang positif darimasyarakat lokal, dimana masyarakat sangat optimis terhadap pengembangan Kebun Raya Gianyar nantinya dapat menjadi destinasi pariwisata unggulan. Hal tersebut tidak lepas dari kekayaan alam yang masih terjaga dari dulu hingga kini. Posisi Kebun Raya Gianyar juga terbilang strategis terletak diantara dua kawasan pariwisata ubud dan kintamani yang didukung dengan akses yang baik memperkuat keoptimisan masyarakat lokal terhadap pengembangan Kebun Raya Gianyar.

Grafik 3.2.1

Sikap Masyarakat Lokal dalam Pengembangan Kebun Raya Gianyar

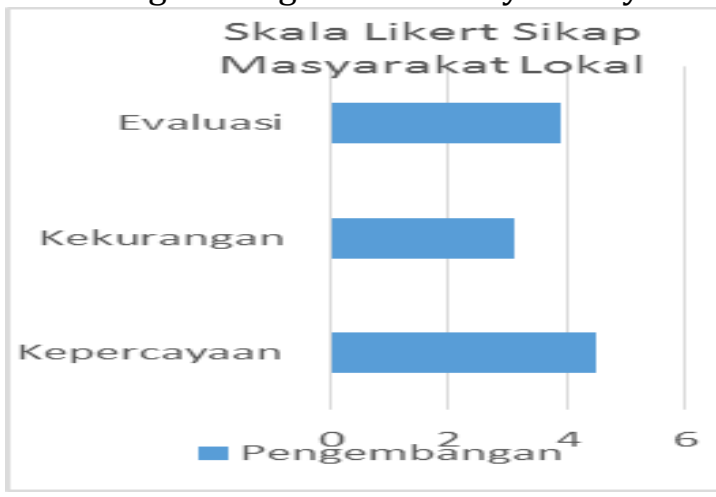

Sikap yang diberikan oleh masyarakat lokal dalam pengembangan Kebun Raya Gianyar yaitu masyarakat telah memberikan kepercayaan yang besar terhadap pengembangan Kebun Raya Gianyar. Hal tersebut berdasarkan nilai rata - rata yang masyarakat berikan yaitu sebesar 4,4 atau sangat setuju. Kepercayaan masyarakat lokal ini berperan penting dalam keberlanjutan Kebun Raya Gianyar kedepannya. Diluar dari kepercayaan masyarakat lokal tersebut, masyarakat sebaliknya menilai bahwa pengembangan Kebun Raya Gianyar belum optimal. Berdasarkan nilai yang diperoleh yaitu 3,1 atau cukup menunjukkan bahwa masyarakat merasakan Kebun Raya Gianyar masih memiliki kekurangan dalam pengembangannya sebagai sebuah destinasi pariwisata. Hal tersebut tidak terlepas dari masih minimnya atraksi dan fasilitas serta pelayanan tambahan yang disediakan oleh Kebun Raya Gianyar. Evaluasi yang telah dilakukan terhadap kekurangan kekurangan tersebut diberi nilai rata - rata 3,9 oleh masyarakat lokal yang diartikan masyarakat lokal merasa kekurangan dalam pengembangan Kebun Raya Gianyar telah dievaluasi dengan baik oleh pihak pengelola. 
Sikap masyarakat lokal dalam pengembangan Kebun Raya Gianyar sebagai suatu destinasi pariwisata yang positif atau baik ini menunjukan bahwa masyarakat lokal menerima kehadiran pariwisata dan melihat pariwisata tersebut sebagai peluang usaha. Hal ini menunjukan bahwa sikap masyarakat lokal euphoria dalam teori irritation index.

\subsubsection{Persepsi Masyarakat Lokal}

Penetapan hutan adat Pilan sebagai Kebun Raya Gianyar bermaksud untuk menjaga serta melestarikan keanekarangaman flora dan fauna yang ada didalamnya serta menjadi sarana pendidikan atau penelitian dan dapat menjadi destinasi pariwisata. Dengan ditetapkannya hal tersebut diharapkan dapat menjaga kelestarian hutan adat itu sendiri serta dapat membantu meningkatkan perekonomian masyarakat lokal.

Grafik 3.2.2

Persepsi Masyarakat Lokal dalam Pengembangan Kebun Raya Gianyar

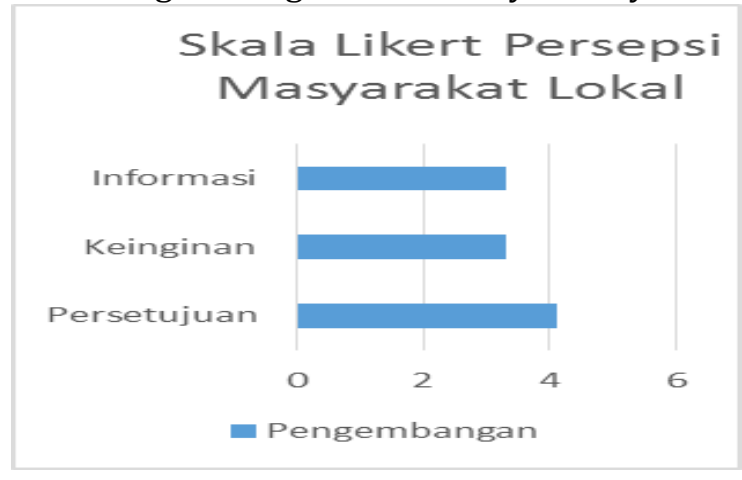

Grafik di atas menegaskan jika persetujuan yang diberikan masyarakat lokal dengan pengembangan Kebun Raya Gianyar sangat tinggi, dimana masyarakat lokal memberikan nilai rata - rata sebesar 4,1 atau sangat setuju. Hal ini menunjukan bahwa pengembangan Kebun Raya Gianyar sebagai destinasi pariwisata di Desa Kerta telah mendapatkan persetujuan masyarakat lokal. Sejalan dengan hal tersebut, keinginan masyarakat lokal dalam pengembangan Kebun Raya Gianyar juga sudah cukup terpenuhi. Terbukti dari nilai rata - rata yang diberikan oleh masyarakat lokal sebesar 3,1 atau cukup. Masyarakat lokal sudah cukup puas dengan pengembangan yang dilakukan dalam aspek aksesibilitas, namun masyarakat lokal kurang puas terhadap pengembangan atraksi dan fasilitas di Kebun Raya Gianyar. Informasi pengembangan Kebun Raya Gianyar kepada masyarakat telah disampaikan dengan cukup baik oleh pihak pemerintah maupun pengelola. Masyarakat memberikan nilai rata - rata 3,1 pada penyampai informasi yang berarti cukup. Dari ketiga variable tersebut dapat dikatakan bahwa persepsi masyarakat dalam pengembangan Kebun Raya Gianyar cukup positif, dimana masyarakat telah menyetujui pengembangan Kebun Raya Gianyar, telah terpenuhinya keinginan masyarakat lokal dan informasi tentang pengembangan Kebun Raya Gianyar telah disampaikan dengan cukup baik.

\subsubsection{Partisipasi Masyarakat Lokal}

Partisipasi masyarakat lokal dalam pengembangan Kebun Raya Gianyar terdiri dari tiga partisipasi yaitu partisipasi spontan, partisipasi terdorong dan terpakasa. Namun partisipasi yang lebih banyak diberikan oleh masyarakat lokal adalah berpartisipasi secara spontan atau secara sukarela. Hal tersebut dapat dilihat pada grafik.

Grafik 3.2.3

Partisipasi Masyarakat Lokal dalam Pengembangan Kebun Raya Gianyar

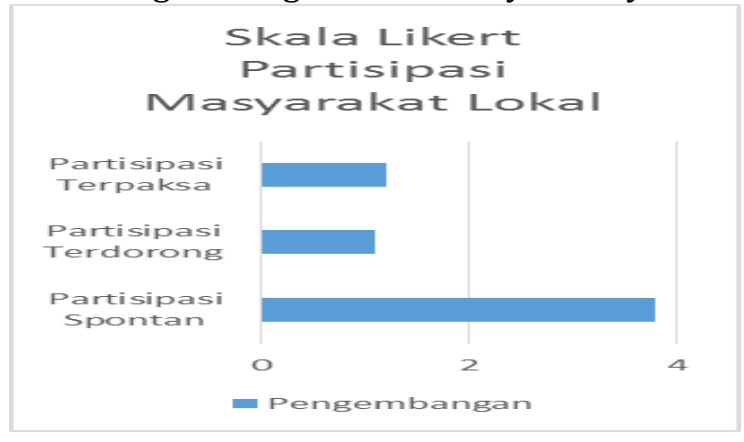

Partisipasi yang diberikan masyarakat lokal dalam pengembangan Kebun Raya Gianyar seperti didalam grafik masyarakat lokal lebih banyak memberikan partisipasi mereka secara spontan atau secara sukarela. Hal tersebut dibuktikan dengan nilai rata - rata yang diberikan oleh masyarakat lokal sebesar 3,7. Partisipasi yang diberikan masyarakat lokal melalui 
partisipasi terdorong dan terpaksa sangat kecil yaitu mendapatkan nilai rata 2 dan 1,9.

Partisipasi secara spontan yang nilainya paling banyak ini diberikan oleh masyarakat lokal dalam pengambilan keputusan. Dimana keputusan atau persetujuan yang diberikan masyarakat lokal dalam pengembangan Kebun Raya Gianyar sangat penting. Dengan kata lain, tanpa adanya persetujuan dari masyarakat lokal maka pembangunan di Kebun Raya Gianyar tidak dapat berjalan sebagaimana mestinya. Oleh karena persetujuan tersebut, tingkat kepekaan masyarakat lokal terletak pada Euphoria dalam Irridex karena masyarakat lokal sangat menyambut kehadiran pariwisata di wilayah mereka.

\section{IV.PENUTUP}

\subsection{Simpulan}

Respon masyarakat lokal terdiri dari tiga aspek yakni sikap, persepsi dan partisipasi. Sikap masyarakat lokal dalam pengembangan Kebun Raya Gianyar sangat baik, dimana masing - masing variable mendapatkan nilai rata - rata 4,3 atau sangat baik pada kepercayaan masyarakat lokal, 3 atau cukup pada kekurangan dalam pengembangan Kebun Raya menurut masyarakat lokal dan 3,9 pada evaluasi terhadap kekurangan pengembangan Kebun Raya Gianyar.

Persepsi masyarakat dalam
pengembangan Kebun Raya Gianyar juga sangat baik. Masyarakat lokal telah setuju dengan dikembangkannya Kebun Raya Gianyar dengan nilai rata - rata yang diberikan oleh masyarakat lokal yaitu 4,1 atau sangat setuju. Keinginan masyarakat lokal juga telah terpenuhi dengan nilai rata - rata 3,1 atau cukup dan informasi pengembangan Kebun Raya Gianyar kepada masyarakat lokal telah dilaksanakan dengan baik yaitumendapat nilai rata - rata 3 .

Partisipasi masyarakat lokal jika dilihat dari nilai rata - rata yaitu 3,7. Partisipasi terdorong dan terpaksa sangat kecil yaitu mendapatkan nilai rata 2 dan 1,9.

Secara menyeluruh respon masyarakat lokal dalam pengembangan Kebun Raya Gianyar sangat positif. Respon masyarakat lokal dalam pengembangan Kebun Raya Gianyar masuk kedalam euphoria dalam Irridex.

\subsection{Saran}

Saran untuk penelitian ini adalah:
1. Pengelola Kebun Raya Gianyar diharapkan dapat memberi kesempatan kepada masyarakat lokal untuk berpartisipasi pada pengelolaan Kebun Raya Gianyar sehingga masyarakat lokal ikut merasakan dampak dari keberadaan Kebun Raya Gianyar sebagai secara perekonomian, lingkungan, sosial dan budaya.Untuk wisatawan diharapkan agar selalu mengikuti dengan baik arahan yang diberikan oleh instruktur atau pemandu wisata serta mentaati peraturan-peraturan yang telah dibuat oleh pihak pengelola wisata paralayang.

2. Kondisi akses yang berlubang atau memerlukan perbaikan pada beberapa titik menuju Kebun Raya Gianyar harus diperhatikan oleh pemerintah agar nantinya tidak mengganggu kenyamanan dan keamanan pengunjung dalam berkendara.

\section{DAFTAR PUSTAKA}

Adikampana, I. M., Pujani, L. P. K., \& Nugroho, S. (2015) Partisipasi Masyarakat Lokal dalam Pengembangan Kawasan Pariwisata Candidasa. Jurnal Kajian Bali (Journal of Bali Studies), 8(1), 5370.

Arida, S. (2006). Krisis lingkungan Bali dan peluang ekowisata. INPUT: Jurnal Ekonomi dan Sosial, 1(2)

Anonim. (2008). Peraturan Presiden Republik Indonesia No. 93 Tahun 2011 tentang Kebun Raya. Pemerintah Negara Kesatuan Republik Indonesia.

Abdillah, F., Damanik, J., Fandeli, C., \& Sudarmadji, S. (2015). Perkembangan Destinasi Pariwisata dan Kualitas Hidup Masyarakat Lokal. MIMBAR, Jurnal Sosial dan Pembangunan, 31(2), 339-350.

Doxey, G. (1975). A Causation Theory of Visitor-Resident Irritants: Methodology and Research Inferences. The Impact of Tourism. In the Sixth Annual Conference Proceedings, pp.195-198. San Diego: The Travel Research Association.

Evita, R., Sirtha, I. N., \& Sunartha, I. N. (2012). Dampak perkembangan pembangunan sarana akomodasi wisata terhadap pariwisata berkelanjutan di Bali.Jurnal Ilmiah Pariwisata. Denpasar: Universities Udayana.(16 Juni 2014, 6: 05 PM).

Gunarsa, I. N. (2016). Respon Masyarakat Lokal terhadap Pengembangan Pariwisata di Kelurahan Seminyak, Kecamatan Kuta, Kabupaten Badung. Skripsi. Universitas Udayana. 
Gunawan, I. M. (2016). Pengembangan Agrowisata untuk Kemandirian Ekonomi dan Pelestarian Budaya di Desa Kerta, Payangan Gianyar. Jurnal Master Pariwisata (JUMPA).

Khan, Maryam. (2003). Ecoserv. USA: Howard University

Swastha, Basu \& T. Hani Handoko. (1997). Manajemen Pemasaran, Analisis dan Prilaku Konsumen. Yogyakarta: BPFE. 